\title{
Lawrence Zalcman: A Mathematical Biosketch
}

\section{Peter Duren}

Published online: 20 April 2014

(c) Springer Basel 2014

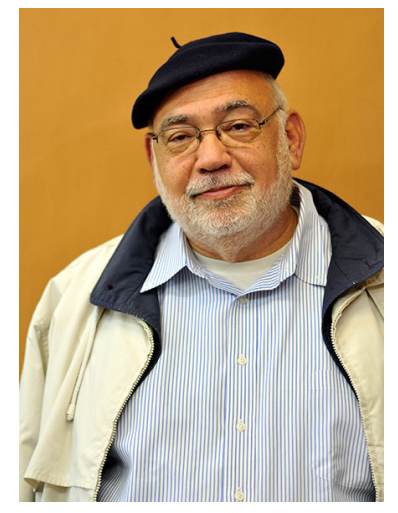

This issue of Analysis and Mathematical Physics is dedicated to Lawrence Zalcman on the occasion of his 70th birthday. Larry is well known for the originality of his mathematics and the quality of his mathematical writing. His credentials in both areas have been well documented in a tribute by Mark Agranovsky and David Shoikhet [AS], prepared for Larry's 60th birthday. Rather than recapitulate material so thoroughly discussed in this earlier sketch of Larry's career, the present article will focus on two questions not addressed there:

1. How did Larry happen to become a mathematician?

2. What has he done in the last 10 years?

To answer the first question, we have to begin at the beginning. Lawrence Zalcman was born in Kansas City, Missouri (USA) on June 9, 1943, the elder son of Max and

\footnotetext{
P. Duren ( $\varangle)$

University of Michigan, Ann Arbor, USA

e-mail: duren@umich.edu
} 
Anna (née Dreiseszun) Zalcman. Both parents were born in pre-WWI Europe, close to the point where the borders of Poland, Belarus, and Ukraine now meet. It was Russia when they were born, Poland when they left (separately), and now lies in Ukraine. Anna came to the U.S. with her family in 1921 and grew up in Kansas City, where other relatives had previously settled. Max grew up in Poland and emigrated to the States in 1932. They met in New York in 1938, married the next year, and eventually settled in Kansas City, where Max established himself in the grocery business and, later, in the retail liquor business. Larry's younger brother and only sibling, Dr. Steven J. Zalcman, studied medicine at Washington University and is a board certified psychiatrist; for many years he has been Chief of the Clinical Neuroscience Research Branch at the National Institute of Mental Health.

Larry received his primary and secondary education in the public schools of Kansas City. At Southwest High School he found a strong and sympathetic math teacher, Alma Shipley (later Crosby), who recognized his talent and encouraged his development. He spent two years in her "Special Math" classes, where topics such as set theory really caught his interest. Miss Shipley also arranged for him to spend the summer between his junior and senior years attending an NSF summer institute run by Dartmouth College at Phillips Academy Andover, where Dartmouth faculty treated the participants to college-level courses in elementary number theory and finite math. It was this experience that started Larry on his career path as a mathematician.

In his senior year in high school, Larry won a prestigious General Motors National Scholarship, which he chose to take to Dartmouth. There he found a most stimulating environment, with a group of outstandingly talented math students and courses taught by such eminent mathematicians as A.S. Besicovitch (complex variables), M. Cotlar (functional analysis), and A.W. Tucker (game theory). During summers, he worked at Midwest Research Institute in Kansas City under Yudell Luke, one of the world's leading experts on Bessel functions. By the time Larry graduated from Dartmouth, after just 3 years, he had taken enough graduate level math courses to exempt the entire MIT graduate course requirement! At MIT, Larry studied complex variables with Henry McKean and functional analysis with Kenneth Hoffman, under whom he wrote his dissertation [7], "Bounded analytic functions on domains of infinite connectivity." It was at MIT also that he published his book Analytic Capacity and Rational Approximation, which brought him instant fame. It was a scholarly account of topics under active development at the time, with clear expositions of deep contributions by the Soviet mathematicians Vitushkin and Melnikov. The book quickly became the standard reference for these topics in function algebras, studied by mathematicians around the world. (For instance, we studied the book in our seminar at Michigan.) Needless to say, it was quite remarkable that such an influential book was produced by a graduate student!

Upon graduation in 1968, Larry became an Assistant Professor at Stanford, then a major center for analysis with a faculty that included Max Schiffer, Stefan Bergman, Halsey Royden, Paul Cohen, Yitzhak Katznelson, Ralph Phillips, and other distin-

\footnotetext{
1 Numbered references refer to the list of Larry's mathematical papers in the Scientific Bibliography contained in this volume. All other references are to the bibliography at the end of this article.
} 
guished mathematicians. (For Larry's own account of his interactions with Schiffer, see [78].) Inspired by a question asked by a student at Stanford, Larry became interested in generalizations of Morera's theorem and found an amazing connection with the zeros of Bessel functions. In his paper [11], which he dedicated to his high-school math teacher Alma Shipley Crosby, he proved that if a function $f \in C\left(\mathbb{R}^{2}\right)$ satisfies $\int_{\Gamma} f(z) d z=0$ for every circle $\Gamma$ of radius $r_{1}$ and $r_{2}$, then $f$ is an entire function, provided that $r_{1} / r_{2}$ is not equal to a quotient of zeros of the Bessel function $J_{1}(z)$; if $r_{1} / r_{2}$ is such a quotient, $f$ need not be analytic at any point. In [12], these results were elaborated and generalized to the solutions of any differential equation of the form $P(D) f=0$, where $P$ is a homogeneous polynomial in $n$ variables and $D=\left(\frac{\partial}{\partial x_{1}}, \frac{\partial}{\partial x_{2}}, \ldots \frac{\partial}{\partial x_{n}}\right)$.

In 1972, Larry moved to a tenured position at the University of Maryland. There, he and his colleague Carlos Berenstein further generalized the results of [11] to spaces of constant curvature [17] and to symmetric spaces of rank one [21]. Around 1975, Larry embarked on another line of research that continues to occupy him to this day: the theory of normal families of analytic and meromorphic functions. According to a heuristic principle attributed to André Bloch, a family of analytic functions with a common property $P$ in a domain $D$ of the complex plane is (apt to be) a normal family in $D$ if the only entire functions with the property $P$ are the constant functions. Abraham Robinson, in his retiring Presidential address to the Association for Symbolic Logic [R] had cited Bloch's Principle as worthy of explication. Larry provided such an explication in [15]. The key to his analysis was a result, now known as Zalcman's Lemma, giving a precise necessary and sufficient condition for a family of analytic (or meromorphic) functions not to be normal.

Around the same time, Larry also wrote [14], a masterpiece of exposition that won him both a Lester R. Ford Award and a Chauvenet Prize. Later he won another Ford Award for his paper [20]. Other outstanding expository articles are [23] and [40].

During his time on the Maryland faculty, Larry held visiting positions at several institutions in Israel. His first long-term stay in that country was in 1970-71, when he took leave from Stanford to visit the Hebrew University with support from a NATO Postdoctoral Fellowship. Eventually, Bar-Ilan University made him an "offer he couldn't refuse," and in 1985 the Zalcman family moved to Israel for good. He retired from Bar-Ilan in 2011 as Professor Emeritus, but continues to serve as Editor of Journal d'Analyse Mathématique, a position he has held since 1987. In 1997-99, Larry was President of the Israel Mathematical Union.

A glance at the Scientific Bibliography of Larry's publications contained in this volume provides the answer to our second question, "What has Larry done lately (i.e., in the past 10 years)?" The short answer is that he has published 8 volumes and some 22 papers. As for books, the jewel in the crown is Complex Proofs of Real Theorems (compare the title of [14]), written with Peter Lax and published in the AMS University Lecture Series. This little volume describes itself as "an extended meditation on Hadamard's famous dictum, 'The shortest and best way between two truths of the real domain often passes through the imaginary one.' "It is a beautiful collection of elegant proofs of theorems in classical analysis, number theory, operator theory, etc. by methods of complex analysis. 
Most of the papers deal with normal families and related topics. While any detailed account of the results contained in these articles is obviously out of the question, we can point to a few items of particular interest. For instance, an illustration of the remarkable power of the "soft" methods pioneered by Larry in dealing with problems of hard analysis is offered by the main theorem of [61]: the derivative of a transcendental meromorphic function, all but at most finitely many of whose zeros are multiple, takes on every nonzero complex value infinitely often. This impressive result represents a high-water mark in the application of (quasi)normal family techniques to value distribution theory. Also worthy of special mention is the virtuoso paper [72], which brings to completion the challenging line of investigation initiated in [52]. Other papers shed new light on old themes. For instance, [71] contains a striking generalization of a classical result of Montel and Fatou, and [75] explores in detail what can be said about the convergence properties of subsequences of a completely arbitrary sequence of meromorphic functions on a plane domain.

It may well be that these and other contributions to the theory of normal families will prove to be Larry's most enduring legacy. Already, Zalcman's Lemma has become an indispensable tool in complex analysis, with applications to such varied areas as ordinary differential equations, complex dynamics, value distribution theory, quasiregular mappings in space, and minimal surfaces [40].

Larry has visited China six times and has cultivated extensive contacts in the community of complex analysts there. One result of this has the been the large number of papers he has written with one or more Chinese coauthors, most of whom he has mentored at Bar-Ilan as postdocs and then, on subsequent visits, as research associates. Larry points to them as a major factor in having kept him "mathematically young" and is very proud of their accomplishments. He is equally proud of his student, colleague, and collaborator Shahar Nevo, who has established himself as a leading authority in the subject of quasinormal families of analytic and meromorphic functions.

Larry and his wife Adrienne met at a party in New York on Larry's 21st birthday, just a week before his graduation from Dartmouth. Larry says it was love at first sight. They became engaged at the end of the summer and were married on July 5, 1965. Adrienne has degrees in foreign language education from Boston University and the University of Maryland, and she taught Spanish for a while. She has been actively involved in the world of Israeli folk dancing in both Maryland and Israel. She also paints with oils and acrylics on canvas. Larry and Adrienne have a son and a daughter, Joel and Shulamit, and six grandchildren. All live close to each other in Jerusalem. Adrienne is particularly proud of having taught her grandchildren English in a Hebrew-speaking environment, by reading books with them for hours on end when they were small.

If I may be permitted to close on a personal note, let me say that Larry and I have known each other for almost 50 years. We first became acquainted when Larry wrote to ask me for a reprint. It turned out that he was a graduate student at MIT, living on the same street in Cambridge where I had lived during the first year of my graduate work at MIT. When he took a postdoctoral position at Stanford, just as I had done, we joked that he was following in my footsteps! At Stanford, Max Schiffer was a mentor to us both. Recently, Larry and I worked together to edit the selected papers of Schiffer. It was our first collaboration, and an exhilarating experience to pay tribute to the man who had meant so much to both of us. In a sense, this sketch of Larry's career is also a 
collaboration, for Larry and Adrienne cheerfully answered my questions and provided facts that only they could provide. And so, with thanks to both of them, I say, "Happy Birthday, Larry!"

\section{References}

[AS] Mark Agranovsky and David Shoikhet, Lawrence Zalcman at Sixty, Complex Analysis and Dynamical Systems II, Contemporary Math. 382, Amer. Math. Soc., Providence, RI, 2005, pp. 1-6.

[R] Abraham Robinson, Metamathematical problems, J. Symbolic Logic 38 (1973), 500-516. 